\title{
Improving the Capacity of Surveillance Actors in Transforming SORMAS Data into Evidence-Informed Decision Making on COVID-19 Response in Nigeria
}

Chijioke Igwe Akpa ${ }^{1 *}$, Obiageli Ifeoma Ikwuka ${ }^{2}$, Ermel Johnson ${ }^{3}$, Ed Nwobodo ${ }^{4}$, David Chibuike Ikwuka ${ }^{4}$, Gabriel Ejike Igbokwe $^{5}$, Maxwell Obubu ${ }^{6}$

\author{
${ }^{1}$ Surveillance Support Officer, Nigerian Centre for Disease Control \\ ${ }^{2}$ Department of Educational Foundations, Nnamdi Azikiwe University Awka, Nigeria \\ ${ }^{3}$ West African Health Organization, 175, Avenue Ouezzin Coulibaly, 01BP:153 Bobo Dioulasso 01, Burkina Faso \\ ${ }^{4}$ Department of Human Physiology, Nnamdi Azikiwe University Awka, Nigeria \\ ${ }^{5}$ Department of Applied Biochemistry, Nnamdi Azikiwe University Awka, Nigeria \\ ${ }^{6}$ Senior Technical Officer, Health Systems Consult Limited, Abuja, Nigeria \\ ${ }^{6}$ Department of Statistics, Nnamdi Azikiwe University Awka, Nigeria
}

DOI: $10.36347 /$ sasjm.2022.v08i01.003

| Received: 03.12.2021 | Accepted: 10.01.2022 | Published: 14.01.2022

*Corresponding author: Chijioke Igwe Akpa

Surveillance Support Officer, Nigerian Centre for Disease Control

The objective of disease surveillance and response is to improve the flow of information to monitor the spread of Infectious diseases, evaluate the effectiveness of control and preventive measures. This study assessed surveillance actors' knowledge and capacity to access and utilize relevant evidence from COVID-19 response data. The study was carried out in Anambra State. We adopted a pre-test and post-test design for the study. The population included all the surveillance actors in Anambra state, and the sample was 32 surveillance actors drawn from 42 initial invited actors via accidental sampling. Demographic data and pre-test were administered before the one-day intensive training. After the training, a post-test was administered. Data collected were analyzed using means and standard deviations, and the Chi-square test was used to determine relationships between categorical variables. The study results revealed that there is an increase in the mean of knowledge and capacity amongst the respondents. The findings of this study suggest that ICT competence relevant to data analysis and translating data into Evidence-Informed Decision making (EIDM) can be enhanced through training workshops. This study recommends a conscious effort to institutionalize training, capacity building, and mentoring for knowledge sharing and sustainability of EIDM.

Keywords: Surveillance, SORMAS data, Infectious diseases, Surveillance actors, COVID-19, EIDM, Nigeria.

Copyright $\odot 2022$ The Author(s): This is an open-access article distributed under the terms of the Creative Commons Attribution 4.0 International License (CC BY-NC 4.0) which permits unrestricted use, distribution, and reproduction in any medium for non-commercial use provided the original author and source are credited.

\section{INTRODUCTION}

Managing infectious diseases requires a rapid and effective response to support decision-making. The decisions are complex and require an understanding of the diseases, disease intervention and control measures, and the disease-relevant characteristics of the local community (Standley et al., 2018). Disease surveillance and response improve the flow of surveillance information to monitor disease spread and evaluate the effectiveness of control and preventive measures. Integrated Disease Surveillance and Response (IDSR) tool and Surveillance Outbreak Response Management and Analysis System (SORMAS) capture all the surveillance data on COVID-19 and other Vaccine prevented Diseases (VPD) in Nigeria. Having a robust database is not enough, but data must be analyzed and transformed into evidence-informed decision-making.

There is a large, growing, and disparate evidence-based relevance to Evidence-Informed Decision Making (EIDM), spanning a wide range of disciplines. (Punton et al., 2016). EIDM is when people who need to make choices use the best available evidence to motivate their decisions. Evidence can refer to scientific research but equally so to citizens' voices, SORMAS data, or expert opinion, among other sources. EIDM aims to use the best available evidence for the decision at hand. It aims for evidence that is fit-forpurpose, suitable for the context, and scalable for the decision to be taken. (africaevidencenetwork.org). 
Among the many barriers to evidence use in decision-making, the weak capacity for use has attracted much focus in the last decade (Uneke et al., 2010). Therefore, there is a need to strengthen evidence use by presenting and discussing the experiences on COVID-19 response to strengthen individual and institutional capacity for evidence use amongst the surveillance actors. Developing the capacity of decision-makers to use research evidence through building knowledge, skills, commitment, relationships, and systems will allow for access, appraisal, and application of good quality evidence more effectively when forming policy. The use of research evidence will improve the quality of policies, ultimately benefitting more poor people. Capacity development is a complex and multi-dimensional process that demands and involves more than a focus on individual skills, requiring intervention at individual, interpersonal, organizational, and institutional levels.

Studies examining individual-level interventions, particularly training, suggest combining classroom learning with on-site projects and actively engaging participants'. Organizations may link to training success, especially as supporting organizations appeared to be an important contextual factor influencing training impact. One helpful way of understanding the mechanism through which training can improve capacity is the self-efficacy theory training increases participants' confidence in their capability to perform a specific task or handle a particular situation. (Punton et al., 2016). Reports relating to interpersonal-level interventions discussed the role of networks, knowledge brokers, and champions in promoting EIPM. Individuals can lead to change through the mechanisms of 'cheerleading,' acting as 'transformational leaders' or 'network facilitators,' or promoting 'social learning' through rolemodeling EIPM behaviors. Effective champions and knowledge brokers appear to possess specific interpersonal skills, vision and commitment, and an appropriate level of seniority in an organization. The evidence on networks suggests they may lead to change through the mechanism of 'social processing' - in which beliefs within a group shift towards a consensus which may lead away from EIPM and towards it. (Punton et al., 2016).

Training and mentorship programs in EIDM effectively improved the competencies of civil servants. However, such programs need to train a critical mass to enhance EIDM practice effectively. (Poot et al., 2018). EIPM tools may also lead to change by increasing the value staff place on evidence by convincing them of data's benefits to decision-making. A virtuous circle may emerge, in which increased use of evidence leads to greater demand for it, and so on (Punton et al., 2016). Although solid individual and institutional capacities are critical in enabling evidence-informed decisionmaking (EIDM), these remain weak in many developing countries for many reasons. Lack of EIDM training programs for civil servants and low priority and investments in strengthening institutional structures and mechanisms for enabling EIDM are some of those reasons (Poot et al., 2018).

This study sought to enhance the capacity of surveillance actors in using evidence-informed decision-making on disease outbreak management and response. This study aims to improve the knowledge and capacity of surveillance actors to access and utilize relevant evidence from COVID-19 response data using ICT. It also assessed the usefulness of training to enhance the capacity of the participants to develop evidence to inform decision-making on COVID-19 response.

\section{MATERIALS AND METHODS Study Area}

This study was carried out in Anambra State. Anambra situates in the southeastern region of Nigeria, with a population of over 4 million residents; Awka is its capital. There are two available tertiary hospitals and several secondary facilities with numerous Primary Healthcare Centers in Anambra State. On COVID-19 response, Anambra state-approved and implemented Incident Action Plan in which surveillance is one of the pillars to ensure a robust response. Disease Surveillance activities are also going on at the health centers and communities.

\section{Study Design}

This study deployed a modified "before and after" intervention study design. This design was used in which outcomes were measured on the target participants. According to the degree of adequacy a 5point liker scale according to the degree of adequacy; 1 $=$ grossly inadequate, $5=$ very adequate. The difference between the before and after measurements were taken to be the impact of the intervention.

\section{Sample size and Sampling Technique}

The participants were 32 actors drawn from Surveillance Actors (LGA DSNO and Contact Tracers). The 32 actors were drawn from the initial invited 42 actors via physical attendance, hence, accidental sampling.

\section{DATA COLLECTION}

A one-day intensive training workshop was organized for Surveillance Actors who had 32 participants in attendance out of 42 that were invited. Topics covered includes: (i). Active Case Search; (ii). Event-Based surveillance; (iii) Use of ICT to explore measure of central tendency; (iv) Capacity development on the use of the internet for evidence synthesis. Prior to the one-day intensive training workshop, a pre-tested, semi-structured interviewer-administered questionnaire was used to collect information from respondents. Information collected included socio-demographic 
characteristics of the respondents such as age, level of education, knowledge on surveillance, knowledge on use of data analysis packages, and knowledge on evidence-informed decision making.

The group discussion was used to understand better COVID-19 response and Active Case Search of diseases based on Case Definitions. The participants demonstrated in-depth knowledge of surveillance activities at the facility and community levels.

\section{Measurement of Variable}

The socio-demographic independent variables are gender and age category. These variables were measured using a structured questionnaire. Gender was coded into two categories: Male and Female. Age category on the other hand was measured using age as at last birthday. Mean and standard deviation was calculated for age. All the other independent variables were measured on the nominal or ordinal scale and were later recoded into two categories. Frequencies and proportions were calculated for categorical variables.

\section{DATA ANALYSIS}

Quantitative data analysis was carried out using the Statistical Package for Social Sciences (SPSS) for the Microsoft Window version 23 software. Frequencies and proportions were calculated for categorical variables, while means and standard deviations were calculated for numeric/quantitative variables. Chi-square test was carried out to determine relationships between categorical variables and statistical significance, and this was said to be present at
$\mathrm{P}>0.05$. The independent variables were sociodemographic characteristics, while the dependent variables were knowledge on surveillance activities and data use for decision making.

Qualitative data analysis commenced documenting the outcome of the group discussions with hand-written notes to ensure completeness of information and inclusion of non-verbal responses. The discussion guide generated the development of a coding framework. The discussion output was read to familiarize and identify any themes in the coding framework. The final coding framework was then applied to all group discussions.

Table-1: Socio-demographic and household characteristics of Respondents:

\begin{tabular}{|l|l|l|}
\hline Variable & $\mathbf{N = 3 2}$ & $\mathbf{\%}$ \\
\hline Gender & $\mathbf{3 2}$ & \\
\hline Male & 7 & 21.88 \\
\hline Female & 32 & 78.12 \\
\hline Age Category & $\mathbf{4}$ & \\
\hline$<25$ & 1 & 3.1 \\
\hline $25-34$ & 5 & 15.6 \\
\hline $34-44$ & 10 & 31.3 \\
\hline$>=45$ & 16 & 50 \\
\hline
\end{tabular}

Data in Table 1 show the socio-demographic characteristics of the respondents. An aggregate of $78.12 \%$ of females and 21.88 males were in attendance. $3.1 \%$ represents $<25$ years category, $15.6 \%$ represents age category of 25-34 years, 34-44 years had $31.3 \%$ while $50 \%$ represented 45 years and above.

Table-2: Distribution of Pre-Test Responses

\begin{tabular}{|l|l|l|l|l|l|l|}
\hline & Statistics & $\begin{array}{l}\text { Total } \\
\text { Response }\end{array}$ & Mean & Median & Mode & $\begin{array}{l}\text { Std/ } \\
\text { Deviation }\end{array}$ \\
\hline 1 & $\begin{array}{l}\text { How would you rate your knowledge and understanding } \\
\text { of surveillance data? }\end{array}$ & 32 & 2.75 & 3 & 3 & 0.88 \\
\hline 2 & $\begin{array}{l}\text { How would you rate your knowledge and understanding } \\
\text { of Active Case Search? }\end{array}$ & 32 & 2.91 & 3 & 3 & 0.78 \\
\hline 3 & $\begin{array}{l}\text { How would you rate your knowledge and understanding } \\
\text { of Contact Tracing? }\end{array}$ & 32 & 2.91 & 3 & 2 & 0.93 \\
\hline 4 & $\begin{array}{l}\text { How would you rate your knowledge and understanding } \\
\text { of Indicator Based Surveillance? }\end{array}$ & 32 & 2.91 & 3 & 3 & 0.96 \\
\hline 5 & $\begin{array}{l}\text { How would you rate your knowledge and understanding } \\
\text { of Event-Based Surveillance? }\end{array}$ & 32 & 2.88 & 3 & 2 & 0.87 \\
\hline 6 & $\begin{array}{l}\text { How would you rate your understanding of case } \\
\text { Investigation using CIF/eCIF Forms? }\end{array}$ & 32 & 2.94 & 3 & 2 & 0.95 \\
\hline 7 & $\begin{array}{l}\text { How would you rate your understanding of data Analysis } \\
\text { tool/ICT packages? }\end{array}$ & 32 & 3.25 & 3 & 3 & 0.88 \\
\hline 8 & $\begin{array}{l}\text { How would you rate your knowledge and understanding } \\
\text { of the internet }\end{array}$ & 32 & 2.5 & 2 & 2 & 0.88 \\
\hline 9 & How would you rate your understanding of data use? & 32 & 2.44 & 2 & 2 & 0.88 \\
\hline 10 & $\begin{array}{l}\text { How would you rate your understanding of moving data } \\
\text { to Evidence in Decision making }\end{array}$ & 32 & 2.81 & 3 & 2 & 0.99 \\
\hline & Average Mean & & $\mathbf{2 . 8 3}$ & $\mathbf{2 . 8}$ & $\mathbf{2}$ & $\mathbf{0 . 9}$ \\
\hline
\end{tabular}


Data in Table 2 show the pre-training mean of knowledge and capacity for using evidence for decision making ranged from 2.44-3.25 and with an average mean of 2.83 from the Likert scale of 5 points.

Table-3: Distribution of Post-Test Responses

\begin{tabular}{|l|l|l|l|l|l|l|}
\hline & Statistics & $\begin{array}{l}\text { Total } \\
\text { Response }\end{array}$ & Mean & Median & Mode & $\begin{array}{l}\text { Std/ } \\
\text { Deviation }\end{array}$ \\
\hline 1 & $\begin{array}{l}\text { How would you rate your knowledge and } \\
\text { understanding of surveillance data? }\end{array}$ & 32 & 3.66 & 4 & 3 & 1 \\
\hline 2 & $\begin{array}{l}\text { How would you rate your knowledge and } \\
\text { understanding of Active Case Search? }\end{array}$ & 32 & 4 & 4 & 4 & 0.82 \\
\hline 3 & $\begin{array}{l}\text { How would you rate your knowledge and } \\
\text { understanding of Contact Tracing? }\end{array}$ & 32 & 3.97 & 4 & 4 & 0.93 \\
\hline 4 & $\begin{array}{l}\text { How would you rate your knowledge and } \\
\text { understanding of Indicator Based Surveillance? }\end{array}$ & 32 & 3.84 & 4 & 4 & 0.85 \\
\hline 5 & $\begin{array}{l}\text { How would you rate your knowledge and } \\
\text { understanding of Event-Based Surveillance? }\end{array}$ & 32 & 3.81 & 4 & 4 & 0.97 \\
\hline 6 & $\begin{array}{l}\text { How would you rate your understanding of case } \\
\text { Investigation using CIF/eCIF Forms? }\end{array}$ & 32 & 3.84 & 4 & 4 & 0.88 \\
\hline 7 & $\begin{array}{l}\text { How would you rate your understanding of data } \\
\text { Analysis tool/ICT packages? }\end{array}$ & 32 & 3.75 & 4 & 4 & 0.88 \\
\hline 8 & $\begin{array}{l}\text { How would you rate your knowledge and } \\
\text { understanding of internet }\end{array}$ & 32 & 3.39 & 4 & 4 & 0.82 \\
\hline 9 & How would you rate your understanding of data use? & 32 & 4 & 4 & 3 & 0.84 \\
\hline 10 & $\begin{array}{l}\text { How would you rate your understanding of moving } \\
\text { data to Evidence in Decision making }\end{array}$ & 32 & 3.97 & 4 & 4 & 0.86 \\
\hline & \begin{tabular}{l} 
Average Mean \\
\hline
\end{tabular} & & $\mathbf{3 . 8 2}$ & $\mathbf{4}$ & $\mathbf{4}$ & $\mathbf{0 . 9}$ \\
\hline
\end{tabular}

Data in Table 3 show the post-training mean of knowledge and capacity for using evidence for decision making ranged from 3.75-4.00 and with an average mean of 3.82 from the Likert scale of 5 points.

\section{Figure 1: Knowledge Gain}

Figure 1 shows an increase in mean knowledge with pre-test and post-test mean scores of 2.82 and 3.82, respectively, from the Likert scale of 5 points. The percentage increase in mean of knowledge and capacity amongst the respondents at the end is $20 \%$.

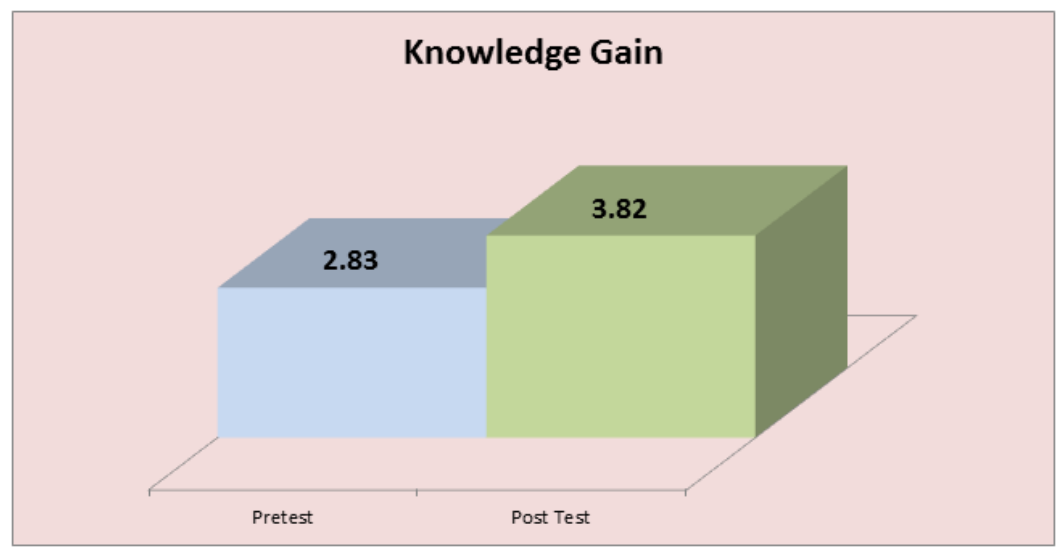

Fig-1: Knowledge Gain

\section{GROUP DISCUSSION RESULTS}

Knowledge of surveillance activities: Most of the respondents demonstrated a good knowledge of case investigation using the COVID-19 case definition. They also have shown understanding of case classification, active case search at the facility and community levels, contact tracing for confirmed cases. They explained routine search for symptoms related to COVID-19 and using community informants for Event-based surveillance.

Some supporting quotes are: "Every case investigation must go with Case Investigation Form (CIF) and must be classified as Suspect case or Probable case or Confirmed case." 
"Every investigated case must be entered into SORMAS and ensured that Epid numbers are assigned to all the cases."

"A well completed Case Investigation Form will help for easy follow-up of patients."

\section{Data Analysis and Data Use for Decision Making}

The respondents expressed limitations on data analysis skills and data use to make decisions. They acknowledged that they enter cases on SORMAS but lack the Information Communication Technology (ICT) skills to analyze the data and translate it to decisionmaking. They believe that their capacity should be built on data analysis and data use for decision making to ensure action for development and improve the effectiveness of implementation efforts.

\section{Improved capacity}

The percentage increase in mean of knowledge and capacity amongst the respondents at the end is $20 \%$. This is significant, as they have shown commitment and enthusiasm for new knowledge. They demanded to be incorporated in existing training programs for sustainability. Strengthening institutional capacity for evidence-informed decision making.

\section{DISCUSSIONS}

This study seeks to improve the capacity of surveillance actors in using evidence to inform decision-making on disease outbreak management and response in Anambra State. The study revealed good knowledge and understanding of surveillance activities by the surveillance actors. Other studies have shown that poor data entry quality and completeness is a significant challenge to evidence-informed decisionmaking. Existing data in the SORMAS platform were reported to be incomplete, making data analysis and usability (for program evaluation and decision-making) almost impossible (Ezenwaka et al., 2020). Poor data quality on SORMAS has been attributed to inadequate human resources and weak capacity to analyze and manage health data at the State and Local Government Area (LGA) levels. In the absence of reliable and usable data, program planning for surveillance will be done abstractly without adequate consideration of contextand population-specific concerns and challenges (Bowen et al., 2005).

There is a capacity gap amongst the respondents on data analysis and translating SORMAS data into Evidence-Informed Decision Making (EIDM). Previous studies have shown that evidence can improve the health system's effectiveness. Therefore, the significance of EIDM amidst the diversity of healthcare needs should be promoted for effective, efficient, and equitable strengthening of the health system (Ezenwaka et al., 2020). Ensuring that evidence from research is used for decision-making is essential to ensure that decision-makers develop and implement the right policies that will be effective and lead to significant improvement in service delivery outcomes (Campbell et al., 2007).

The intervention component of this study contributed to the improved capacity of the respondents. The percentage increase in mean of knowledge and capacity amongst the respondents at the end is $20 \%$. This is significant, as they have shown commitment and enthusiasm for new knowledge. The previous study recognized that intervention/programs are more effective if supported by evidence, enabling better value for money, transparency in decision-making, and accountability. This means that incorporating evidenceinformed into decision-making is critical for health systems responsiveness and successful implementation of endemic disease control programs (Ezenwaka et al., 2020).

\section{CONCLUSION}

Although training and mentorship effectively improve EIDM competencies, they need to be incorporated into existing training programs for sustainability. Strengthening institutional capacity for evidence is complex and needs sustained political commitment and long-term investments. The findings of this study suggest that ICT competence relevant to data analysis and translating data to evidence-informed decision-making can be enhanced through training workshops. There should be a conscious effort to institutionalize training, capacity building, and mentoring for knowledge sharing and evidenceinformed decision-making sustainability. These efforts will help the surveillance actors know their data, interpret it, and use it for decision-making.

\section{REFERENCE}

1. Africa Evidence Network. (Viewed 2021). Available from: www.africaevidencenetwork.org

2. Bowen, S., \& Zwi, A. B. (2005). Pathways to "evidence-informed" policy and practice: a framework for action. PLoS medicine, 2(7), e166.

3. Campbell, D. M., Redman, S., Rychentnik, L., Cooke, M., Zwi, A. B., \& Jorm, L. (2009). Increasing the use of evidence in health policy: practice and views of policy makers and researchers. Australia and New Zealand Health Policy, 6(1).

4. Chu, K. M., Jayaraman, S., Kyamanywa, P., \& Ntakiyiruta, G. (2014). Building research capacity in Africa: equity and global health collaborations. PLoS medicine, 11(3), e1001612.

5. Ezenwaka, U., Mbachu, C., Etiaba, E., Uzochukwu, B., \& Onwujekwe, O. (2020). Integrating evidence from research into decisionmaking for controlling endemic tropical diseases in South East Nigeria: perceptions of producers and users of evidence on barriers and solutions. Health research policy and systems, 18(1), 1-10. 
6. Nigeria. Federal Ministry of Health. (2010). National Strategic Health Development Plan (NSHDP) 2010-2015. Federal Ministry of Health.

7. Gilson, L. (2012). Introduction to health policy and systems research. Health policy and systems research: a methodology reader. Geneva: Alliance for Health Policy and System Research: WHO, 19, 39.

8. Poot, C. C., Van Der Kleij, R. M., Brakema, E. A., Vermond, D., Williams, S., Cragg, L., ... \& Chavannes, N. H. (2018). From research to evidence-informed decision making: a systematic approach. Journal of Public Health,40(suppl_1), i3-i12.

9. Punton, M., Hagerman, K., Brown, C., Echt, L., Fisher, C., Lloyd, R., Morton, S. \& Vogel, I. (2016). How can capacity development promote evidence-informed policymaking? Literature review for the Building Capacity to Use Research Evidence (BCURE) program.

10. Standley, C. J., Graeden, E., Kerr, J., Sorrell, E. M., \& Katz, R. (2018). Decision support for evidencebased integration of disease control: A proof of concept for malaria and schistosomiasis. PLoS neglected tropical diseases, 12(4), e0006328.

11. Uneke, C. J., Ezeoha, A. E., Ndukwe, C. D., Oyibo, P. G., \& Onwe, F. (2010). Development of health policy and systems research in Nigeria: lessons for developing countries' evidence-based health policy making process and practice. Healthcare Policy, 6(1), e109.

12. Uneke, C.J., Ogbonna, A., Ezeoha, A., Oyibo, P.G., Onwe, F., \& Ngwu, B. (2009). Health system research and policy development in Nigeria: the challenges and way forward. Internet Journal of World Health and Societal Politics, 6(2); 11-19. 